\title{
Mechanisms of Rhenium on Wettability and Interactions Between Nickel-Base Superalloy Melt and $\mathrm{Al}_{2} \mathrm{O}_{3}$-Based Ceramic Material
}

\author{
Yun Zi ${ }^{1,2} \cdot$ Jie Meng ${ }^{1} \cdot$ Chaowei Zhang ${ }^{1} \cdot$ Yizhou Zhou $^{1} \cdot$ Yutian Ding $^{3}$
}

Received: 24 September 2019 / Revised: 14 November 2019 / Published online: 25 March 2020

(c) The Chinese Society for Metals (CSM) and Springer-Verlag GmbH Germany, part of Springer Nature 2020

\begin{abstract}
A systematic study on the wettability and interactions between superalloy melts with various $\mathrm{Re}$ contents and $\mathrm{Al}_{2} \mathrm{O}_{3}$-based ceramic moulds was presented in this paper. It was found that the increase of Re content inhibited the interfacial reactions to some extent. With regard to the $0,1.5$ and $3 \mathrm{Re}$ alloys, a double reaction layer containing $\mathrm{Al}_{2} \mathrm{O}_{3}$ and $\mathrm{HfO}_{2}$ was formed at the interface, but the thickness of reaction layer decreased with the increase of Re content. However, only $\mathrm{Al}_{2} \mathrm{O}_{3}$ phase was detected at the interface when the content of Re was $6 \mathrm{wt} \%$, and the interface reaction was the weakest and the thickness of reaction layer was the thinnest. The wetting angle of the alloy/ceramic system increased as the level of Re increased. Moreover, the formation of viscous sand at the interface mainly depended on the change of wetting angle of the system.
\end{abstract}

Keywords Superalloy melt $\cdot \mathrm{Al}_{2} \mathrm{O}_{3}$-based ceramic mould $\cdot$ Interactions $\cdot$ Wettability $\cdot$ Rhenium

\section{Introduction}

Ni-based single-crystal superalloys are developed as metallic materials which present good corrosion resistance and excellent mechanical properties in the condition of high temperatures and complex stresses. They have been widespread used as the turbine blades and vanes in aircraft engines and gas engines in the last few decades [1-3]. These parts are universally produced by investment casting technology, which is an important manufacturing technology to produce superalloy castings with complex structure and shape [4]. During the investment casting of single-crystal superalloys, ceramic

Available online at http://link.springer.com/journal/40195.

Jie Meng

jmeng@imr.ac.cn

$\triangle$ Yizhou Zhou

yzzhou@imr.ac.cn

1 Institute of Metal Research, Chinese Academy of Sciences, Shenyang 110016, China

2 Department of Materials Science and Engineering, University of Science and Technology of China, Hefei 230026, China

3 State Key Laboratory of Advanced Processing and Recycling of Nonferrous Metals, Lanzhou University of Technology, Lanzhou 730050, China mould is usually immersed in the molten alloy for more than $1 \mathrm{~h}$ at high temperatures. Moreover, owing to the presence of reactive elements in the alloy melt, such as $\mathrm{Al}[5], \mathrm{C}[6,7]$, $\mathrm{Cr}[8,9]$, Hf $[10,11]$ and $\mathrm{Y}[12]$, the interface reactions are more likely to occur under such conditions. The reactive elements will capture the oxygen atoms in the ceramic mould and form oxide inclusions on the surface of the alloy, which thereby results in the superficial defects of castings and seriously affects the use of castings [13]. Therefore, eliminating or minimizing the interface reactions is extremely important for improving the quality of superalloy castings.

Understanding the wettability of molten superalloy on the ceramic surface is of great significance to elucidate the interfacial reaction mechanisms. Proper wettability between the alloy and the ceramic is the prerequisite for mould-filling of the castings. If the molten alloy well wets the ceramic mould, the molten alloy will penetrate into the mould through the capillaries on the ceramic surface. Therefore, viscous sand or inclusions will appear on the surface of castings after the cooling. Conversely, if the molten alloy wets the ceramic mould poorly, the castings obtained will be incomplete during the casting, which will increase the scrap rate of castings [14, 15]. As a result, it is necessary to discuss the relationship between interface reactions and wettability in depth.

$\mathrm{Re}$ in the alloy can improve the high-temperature strength of superalloys, and also can increase corrosion and 
oxidization resistance of alloys [16, 17]. Research from Xue showed that Re was an element with stable chemical properties and did not react with ceramic materials [18]. But it has not been mentioned whether the change of Re content affects the wettability and interface reactions. Hence, the purpose of this work is to study the effect of Re content on the wettability and interactions between nickel-base superalloy melt and $\mathrm{Al}_{2} \mathrm{O}_{3}$-based ceramic mould. Meanwhile, the relevant influence mechanisms of Re are elucidated. It provides a theoretical basis for solving the interfacial reaction problem in the actual pouring.

\section{Experimental}

A kind of single-crystal Ni-base superalloy, with the chemical composition (wt\%) of Cr 7.0, Al 6.3, Mo 1.5, Co 7.5, W 5, Ta 6.5, B 0.004, C 0.05, Hf 0.15 and $\mathrm{Ni}$ in balance, is selected in this work. Four alloys with various Re contents were melted in a vacuum induction furnace, and the content of $\operatorname{Re}(\mathrm{wt} \%$ ) was $0,1.5,3$ and 6 , respectively. The alloys used were cut into cubic samples of $5 \mathrm{~mm} \times 5 \mathrm{~mm} \times 5 \mathrm{~mm}$, and the trace of oxides on the alloy surfaces were removed by polishing. Before the experiments, the alloy samples were cleaned with alcohol in an ultrasonic bath.

The ceramic substrate used is a $\mathrm{Al}_{2} \mathrm{O}_{3}$-based ceramic mould material, which is made according to the standard procedure of ceramic mould preparation in the investment casting. Firstly, the melted wax was injected into the metal mould, and then the wax pattern was obtained. Secondly, the ceramic slurry was prepared. The ceramic slurry for preparing the mould consisted of refractory material and liquid binder. The composition of refractory material was $\mathrm{Al}_{2} \mathrm{O}_{3}$ powder (95 $\mathrm{wt} \%$ ) and $\mathrm{SiO}_{2}$ powder (5 $\mathrm{wt} \%$ ), and the particle size of which was -320 mesh. The liquid binder was colloidal silica $\left(30 \mathrm{wt} \% \mathrm{SiO}_{2}\right)$. The ceramic slurry was mixed evenly on the mixer. Thirdly, the wax pattern was immersed in the ceramic slurry, sprinkled with refractory stucco, and dried. The above process needed to be repeated several times until the mould was nearly $5 \mathrm{~mm}$ thick. Finally, the wax pattern was melted out and sintered at $900{ }^{\circ} \mathrm{C}$ for $2 \mathrm{~h}$, and the experimental ceramic moulds were obtained. The ceramic substrates were cut from the moulds, and the dimension was $20 \mathrm{~mm} \times 20 \mathrm{~mm} \times 5 \mathrm{~mm}$. Before the experiments, the ceramic substrates were cleaned with alcohol. The surface line roughness $(\mathrm{Ra})$ of ceramic substrate was measured by using LSM700 laser confocal scanning microscopy, and the level of open porosity of the substrate was measured with reference to GB/T 1966-1996 [19].

The wettability experiments were carried out by using "sessile drop" method in a vacuum induction directional solidification furnace. A ceramic shell with tray was rested in the furnace. The ceramic substrate was placed in the tray and then adjusted it to the horizontal position using a level vial. Subsequently, the alloy was placed on the ceramic substrate. When the vacuum in the furnace was pumped to about $0.01 \mathrm{~Pa}$, the furnace was heated to $1550{ }^{\circ} \mathrm{C}$ and kept for $40 \mathrm{~min}$. After then, the alloy and the ceramic were removed from the furnace. When the alloy was solidified, the wetting angle was calculated by using the formula $\theta=2 \arctan (2 h / d)$ [14], where $h$ and $d$ are the height and the base diameter of the alloy drop, respectively.

After the experiments, the microstructure observation of alloy and ceramic samples was conducted by JMS-6301F field emission-scanning electron microscopy (SEM), and the chemical compositions of reaction products were analysed by using a JXA-8530F electron probe micro-analyser (EPMA). D/Max 2500PC X-ray diffraction (XRD) and ESCALAB250 X-ray photoelectron spectrometer (XPS) were used to identify the phases of reaction products.

\section{Results}

\subsection{Surface Characterization of $\mathrm{Al}_{2} \mathrm{O}_{3}$-Based Ceramic Substrate}

Figure 1 shows the surface morphologies and surface roughness of $\mathrm{Al}_{2} \mathrm{O}_{3}$-based ceramic substrate in the initial state. As can be seen, the ceramic particles are sintered together and a few closed pores are observed inside the sintered ceramic substrate. The surface of ceramic substrate is rough (Fig. 1b), and the surface roughness $\mathrm{Ra}$ of the substrate is determined to be $1.287 \mu \mathrm{m}$ when the open porosity level of ceramic substrate is $12.75 \%$.

\subsection{Wettability of Molten Superalloy on Ceramic Substrate}

The macroscopic images of wetting angles between the four superalloy melts and the ceramic moulds are illustrated in Fig. 2. It is clearly that the change of wetting angle is related chiefly to the content of Re. And the variation trend of wetting angle with various contents of Re is displayed in Fig. 3. As is shown, the wetting angle increases with Re content increasing. With regard to the alloys with Re content of 0 , $1.5,3$ and $6 \mathrm{wt} \%$, the wetting angles of the alloy/ceramic systems are $117.2^{\circ}, 128.5^{\circ}, 132.3^{\circ}$ and $141.7^{\circ}$, respectively. The results indicate that the wettability of the system gradually deteriorates with the increase of Re content.

\subsection{Interfacial Reactions for the Four Alloy/Ceramic Systems}

Figure 4 shows the morphologies of the four alloy bottoms. It can be seen that the interface reaction occurs for 

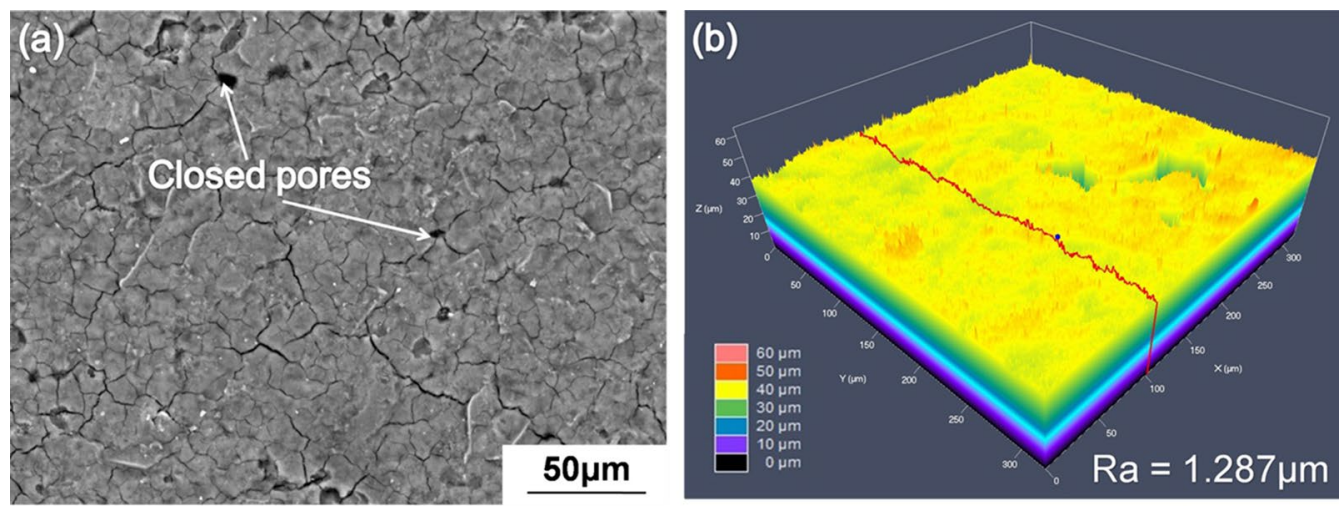

Fig. 1 SEM image (a), 3D image (b) of the surface morphologies of ceramic substrate
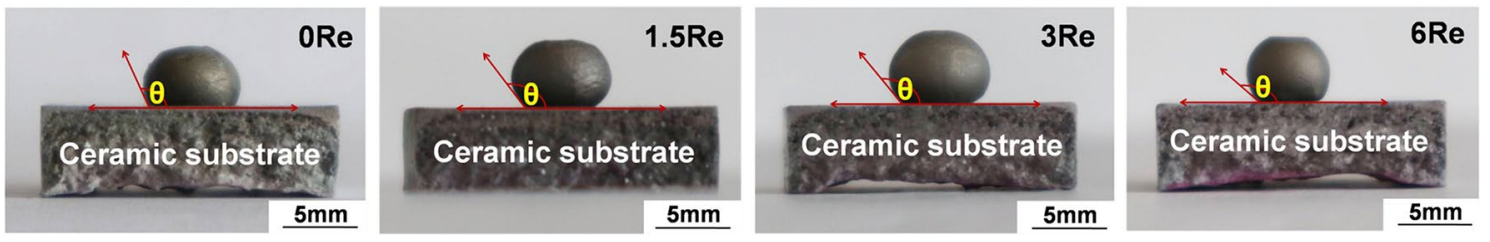

Fig. 2 Macroscopic images of wetting angles between different alloy melts and the ceramics

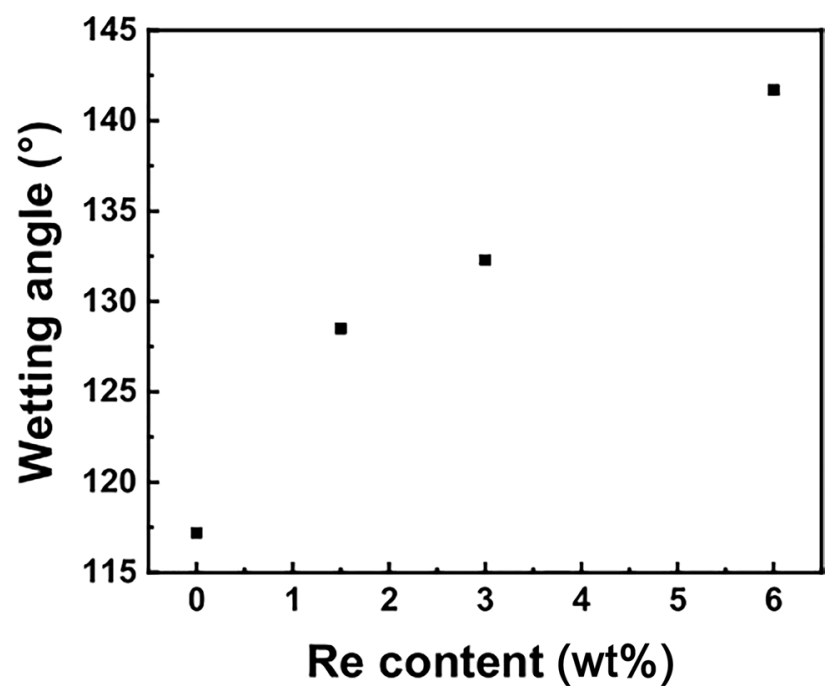

Fig. 3 Variation trend of the wetting angle with various contents of Re

the four alloy/ceramic systems, but the reaction degree is obviously different. As is shown, reaction products and viscous sand are detected at the bottom of the alloys, and the viscous sand is dispersed over the reaction products. The viscous sand takes on a sheet structure, which is similar to the initial ceramic surface. The reaction products present a honeycomb structure. Both reaction products and viscous sand are mainly rich in $\mathrm{Al}$ and $\mathrm{O}$ (Table 1). For the 0Re alloy (Fig. 4a), the interface reaction is the most serious, the whole alloy bottom is covered by reaction products, and the viscous sand is completely mixed with the reaction products. For the 6Re alloy (Fig. 4d), the interface reaction is the weakest, only a few reaction products and viscous sand are observed. For the 1.5 and 3Re alloys (Fig. 4b, c), the viscous sand at the $1.5 \mathrm{Re}$ alloy bottom is more serious than that of 3Re alloy. Based on the results of XRD analysis illustrated in Fig. 5, the same reaction product, $\mathrm{Al}_{2} \mathrm{O}_{3}$, is formed at the bottom of different alloys. Additionally, $3 \mathrm{Al}_{2} \mathrm{O}_{3} \cdot 2 \mathrm{SiO}_{2}$ is the reaction product between $\mathrm{SiO}_{2}$ and $\mathrm{Al}_{2} \mathrm{O}_{3}$ in the ceramic mould after calcination, and the other peaks coincide with those of $\mathrm{Ni}_{3} \mathrm{Al}\left(\gamma / \gamma^{\prime}\right)$ in the alloy (Fig. 5).

The morphologies of longitudinal section of the four alloys are shown in Fig. 6. In the case of 0Re alloy (Fig. 6a), a reaction layer consisting of the reaction products mixed with ceramic particles is observed at the interface, which is roughly $20-30 \mu \mathrm{m}$ thick. When the content of Re is added to 1.5 and $3 \mathrm{wt} \%$ (Fig. 6b, c), a continuous reaction layer in contact with the alloy is detected at the interface, and the reaction layer of $1.5 \mathrm{Re}$ alloy $(5 \mu \mathrm{m})$ is slightly thicker than that of 3Re alloy $(3 \mu \mathrm{m})$. However, when the content of Re increases to $6 \mathrm{wt} \%$ (Fig. 6d), extremely few reaction products are found, and the thickness of reaction layer is less than $2 \mu \mathrm{m}$. Chemical compositions of the interfaces determined by EDS analysis are listed in Table 2 .

Figure 7 shows the surface morphologies of ceramic moulds after the interface reactions. For the 0Re alloy (Fig. 7a), the particles of ceramic surface are severely peeled off, and there are many large holes on the ceramic surface. $\mathrm{A}$ few $\mathrm{Al}_{2} \mathrm{O}_{3}$ is 

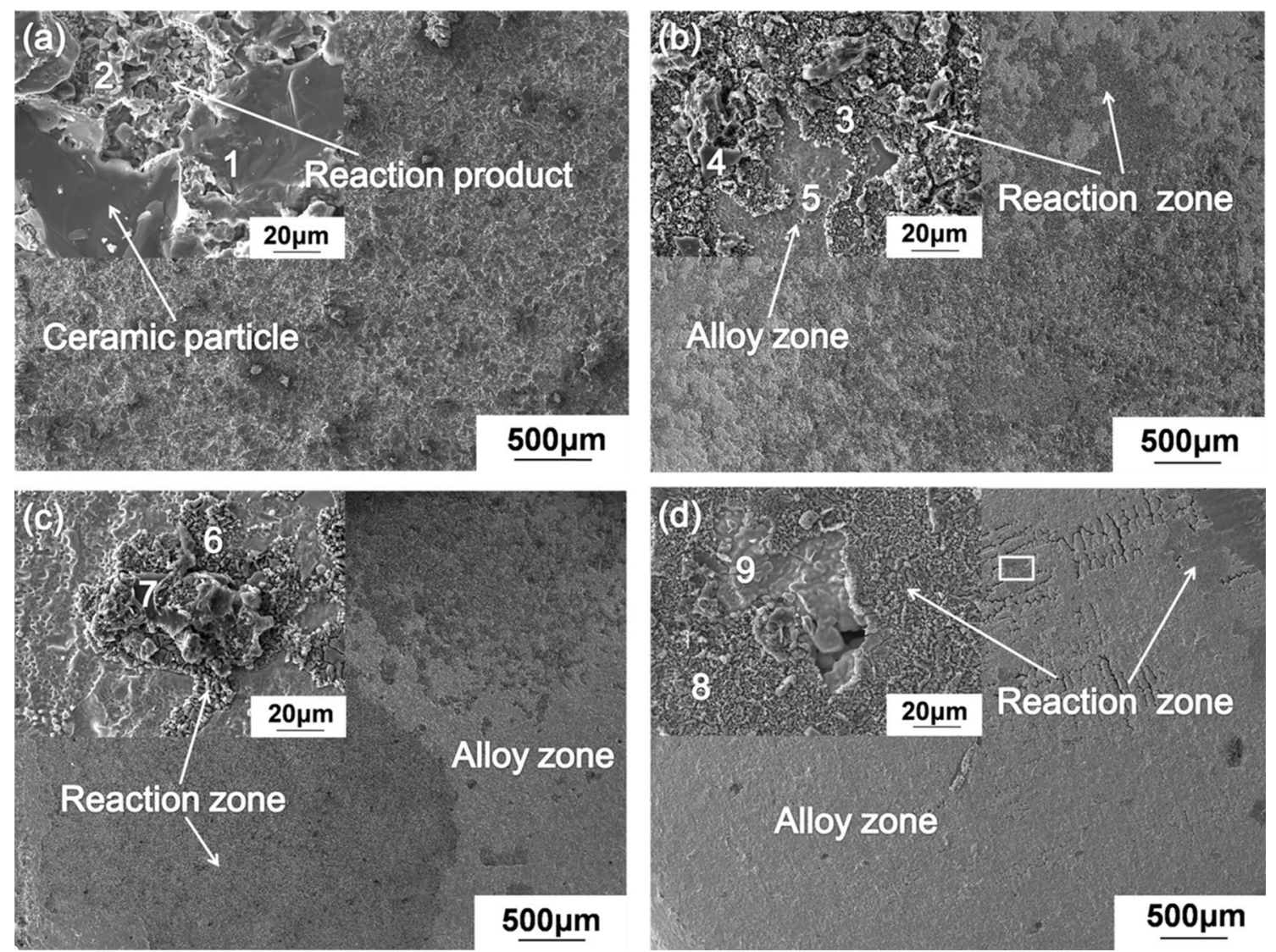

Fig. 4 Morphologies of the four alloy bottoms: a $0 \operatorname{Re}, \mathbf{b} 1.5 \operatorname{Re}, \mathbf{c} 3 \operatorname{Re}, \mathbf{d} 6 \mathrm{Re}$

Table 1 Chemical compositions of the reaction zones in Fig. 4 obtained via EPMA (at.\%)

\begin{tabular}{lrlllllllll}
\hline Position & $\mathrm{Ni}$ & $\mathrm{W}$ & $\mathrm{Ta}$ & $\mathrm{Al}$ & $\mathrm{O}$ & $\mathrm{Cr}$ & $\mathrm{Co}$ & $\mathrm{Mo}$ & $\mathrm{Re}$ & $\mathrm{Si}$ \\
\hline 1 & 0.3467 & - & - & 34.9272 & 53.3338 & 0.2329 & 0.0412 & 0.0027 & 0.0056 & 11.1099 \\
2 & 1.3726 & 0.0281 & 0.0068 & 43.3893 & 54.8898 & 0.0948 & 0.1976 & 0.0127 & 0.0058 & 0.0026 \\
3 & 0.8072 & 0.0066 & - & 44.1792 & 54.8130 & 0.0785 & 0.1155 & - & - & - \\
4 & 0.1768 & 0.0499 & 0.0088 & 45.8245 & 53.9325 & - & - & 0.0074 & - & - \\
5 & 56.7870 & 1.3220 & 2.2166 & 14.0153 & 17.0767 & 1.8132 & 5.9278 & 0.4441 & 0.3974 & - \\
6 & 0.8263 & 0.0201 & - & 41.1192 & 57.8826 & 0.0642 & 0.0812 & - & 0.0065 & - \\
7 & 0.6404 & - & - & 43.6272 & 55.6374 & 0.0437 & 0.0706 & 0.0007 & - & - \\
8 & 1.0203 & 0.0282 & 0.0224 & 42.3081 & 56.4644 & 0.0414 & 0.1151 & - & - & - \\
9 & 58.6180 & 0.1800 & 1.9125 & 16.4942 & 14.1468 & 2.0493 & 5.0551 & 1.0114 & 0.5327 & - \\
\hline
\end{tabular}

adhered to the ceramic surface, and some white particles are dispersed on the $\mathrm{Al}_{2} \mathrm{O}_{3}$ layer. From the results of Table 3, the white particles are rich in $\mathrm{Hf}, \mathrm{Al}$ and $\mathrm{O}$. XRD analysis shows that the ceramic surface is mainly $\mathrm{Al}_{2} \mathrm{O}_{3}$ and $3 \mathrm{Al}_{2} \mathrm{O}_{3} \cdot 2 \mathrm{SiO}_{2}$ (Fig. 8a). For the 1.5 and $3 R$ Re alloys (Fig. 7b, c), the surface ceramic particles partially fall off, and there are reaction products on the ceramic surface. XRD analysis confirms that the white particles are $\mathrm{HfO}_{2}$ (Fig. 8b, c). For the 6Re alloy, no $\mathrm{HfO}_{2}$ phase is found on the ceramic surface. Except for a small amount of $\mathrm{Al}_{2} \mathrm{O}_{3}$ bonded to the surface of the ceramic, there is no obvious change compared with the ceramic surface before the interface reactions (Fig. 7d). 

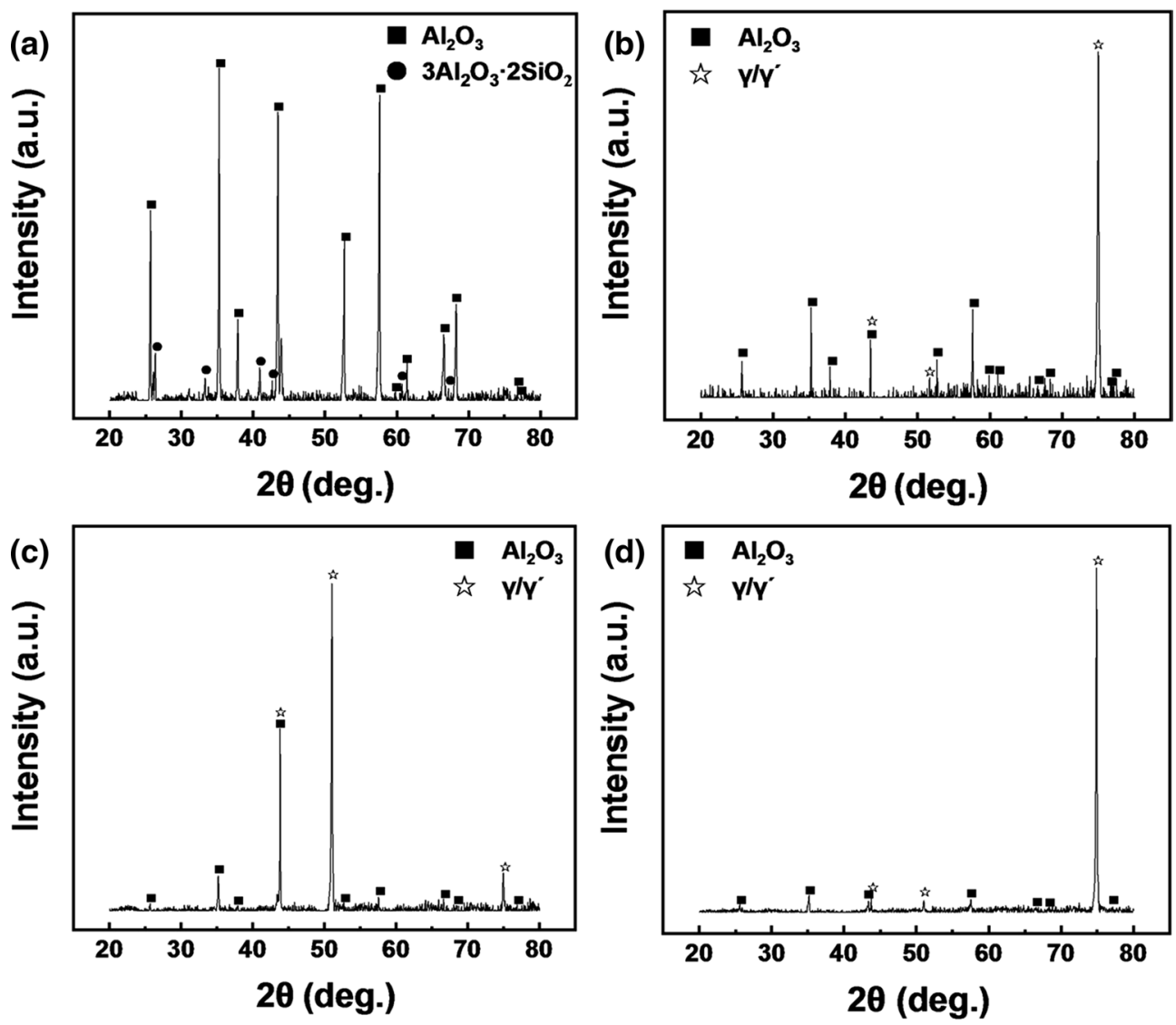

Fig. 5 XRD patterns of the four alloy bottoms: a $0 R e, b 1.5 R e, \mathbf{c} 3 R e, \mathbf{d} 6 \operatorname{Re}$

\section{Discussion}

\subsection{Wettability of Molten Superalloy on Ceramic Substrate}

The wetting angle of the alloy/ceramic system increases from $117.2^{\circ}$ to $141.7^{\circ}$ when the content of Re increases from 0 to $6 \mathrm{wt} \%$, illustrating that the wetting angle is related chiefly to the content of Re in the alloy. In reactive wetting systems, the wetting process of molten alloy on ceramic substrate is influenced by dissolution, diffusion, chemical adsorption and chemical reaction. When interface reaction occurs, chemical reaction will mainly control the wetting process and determine the wettability $[20,21]$. The interface reaction free energy change controlled theory suggested that intense interface reaction was a necessary condition for obtaining good wettability, that is, the more intense the interface reaction was, the better the wettability would be [21]. In present work, the degree of interface reaction decreases with the increase of Re content, so the wettability of the system will deteriorate.

\subsection{Interfacial Reactions}

The above results demonstrate that the interface reactions between different alloy melts and ceramic moulds are dominated by active elements $\mathrm{Hf}$ and $\mathrm{Al}$ in the melt. For the alloys with Re content of $0,1.5$ and $3 \mathrm{wt} \%, \mathrm{Al}_{2} \mathrm{O}_{3}$ and $\mathrm{HfO}_{2}$ phases are formed at the interface. For the alloy with Re content of $6 \mathrm{wt} \%$, only $\mathrm{Al}_{2} \mathrm{O}_{3}$ phase is formed. The reaction products are oxides, and there are two possible sources of oxygen during the investment casting: ceramic mould or oxygen partial pressure in the vacuum furnace. The oxides generated by the reactions only appear at the alloy-ceramic interface, but not at other positions of the alloy. So it can be determined that the oxygen in the reaction products comes from the ceramic mould. $\mathrm{Hf}$ and $\mathrm{Al}$ are reported to react with $\mathrm{SiO}_{2}$, and the reaction equations are as follows $[5,11]$ :

$\mathrm{Hf}+\mathrm{SiO}_{2} \rightarrow \mathrm{HfO}_{2}+\mathrm{Si}$

$\mathrm{Al}+3 / 4 \mathrm{SiO}_{2} \rightarrow 1 / 2 \mathrm{Al}_{2} \mathrm{O}_{3}+3 / 4 \mathrm{Si}$. 

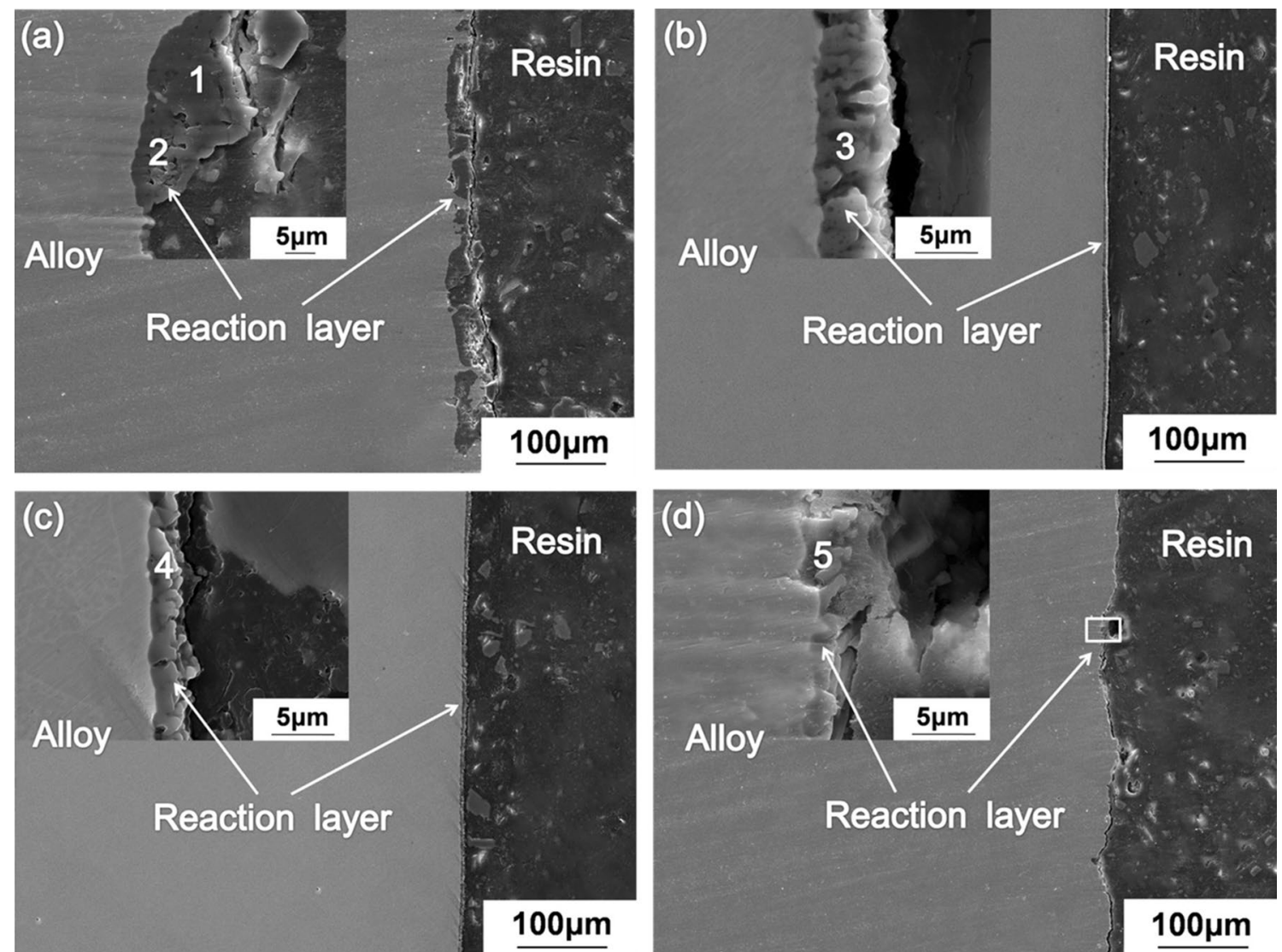

Fig. 6 Morphologies of longitudinal section of the four alloys: a $0 \operatorname{Re}, \mathbf{b} 1.5 \operatorname{Re}, \mathbf{c} 3 \operatorname{Re}, \mathbf{d} 6 \operatorname{Re}$

Table 2 Chemical compositions of the interfaces in Fig. 6 determined by EDS (at.\%)

\begin{tabular}{lllll}
\hline Position & $\mathrm{Al}$ & $\mathrm{O}$ & $\mathrm{Si}$ & $\mathrm{Ni}$ \\
\hline 1 & 33.92 & 50.04 & 16.03 & - \\
2 & 36.05 & 58.93 & 3.40 & 1.62 \\
3 & 43.25 & 55.66 & - & 1.09 \\
4 & 44.81 & 53.72 & - & 1.47 \\
5 & 39.44 & 57.58 & - & 2.98 \\
\hline
\end{tabular}

From the perspective of thermodynamics stability, the stability of the oxides is $\mathrm{SiO}_{2}<\mathrm{Al}_{2} \mathrm{O}_{3}<\mathrm{HfO}_{2}$ [22]. It implies that $\mathrm{Hf}$ can preferentially reduce $\mathrm{SiO}_{2}$ to form $\mathrm{HfO}_{2}$, and then $\mathrm{Al}$ reacts with $\mathrm{SiO}_{2}$ to form $\mathrm{Al}_{2} \mathrm{O}_{3}$.

In terms of the reaction equations, $\mathrm{Si}$ is formed by the reactions. Since no Si-rich phase was detected in the XRD patterns, the Si $2 p$ XPS spectrum of the 3Re alloy bottom is analysed to determine the fate of reaction product $\mathrm{Si}$, which is shown in Fig. 9. According to the NIST XPS database [23] (Table 4), Si at the alloy bottom is oxidized to form $\mathrm{SiO}_{0.93}$. Some reports have indicated that $\mathrm{Si}$ rarely exists as a single substance, and $\mathrm{Si}$ can react with $\mathrm{O}_{2}$ at high temperatures [24]. Therefore, $\mathrm{Si}$ may react with $\mathrm{O}_{2}$ in the atmosphere to form $\mathrm{SiO}_{0.93}$ during the cooling, and the reaction equation can be deduced as follows:

$\mathrm{Si}+x[\mathrm{O}] \rightarrow \mathrm{SiO}_{x}$,

where $\mathrm{SiO}_{x}(0<x<2)$ is non-stoichiometric silicon oxide. In this study, $x=0.93$.

Based on the results in Fig. 4, the reaction products and viscous sand are all mainly $\mathrm{Al}_{2} \mathrm{O}_{3}$, but it is difficult to distinguish them from the XRD patterns. Therefore, $\mathrm{Al}$ and $\mathrm{O}$ are the main elements concerned in the interfacial reactions. Taking the $3 \mathrm{Re}$ alloy as an example, the $\mathrm{Al} 2 p$ and $\mathrm{O} 1 s$ XPS spectra of the alloy bottom are analysed to distinguish the two $\mathrm{Al}_{2} \mathrm{O}_{3}$ phases. The valence states of $\mathrm{Al}$ and $\mathrm{O}$ elements at the alloy bottom can be obtained by analysing the detailed XPS spectra, which are revealed in Fig. 10. The binding energies of the peaks were indexed in accordance with the NIST XPS database [23]. Table 4 lists the binding energies in the literature. It can be seen that $\mathrm{Al}$ exists at the bottom of the alloy in the form of two oxides. One is the reaction product $\mathrm{Al}_{2} \mathrm{O}_{3}$ and the other is 

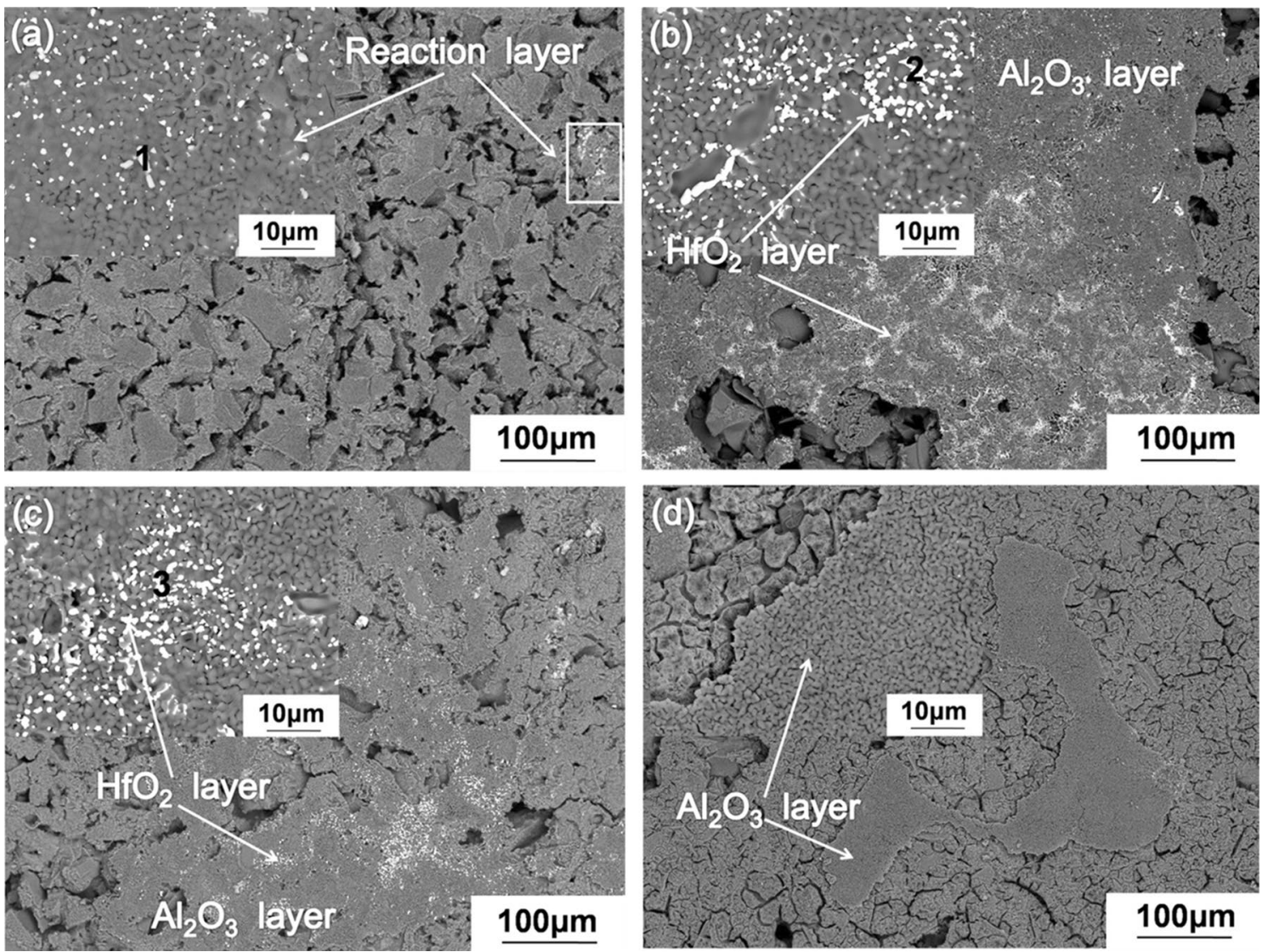

Fig. 7 Surface morphologies of ceramic moulds after the interface reactions: a $0 \operatorname{Re}, \mathbf{b} 1.5 \operatorname{Re}, \mathbf{c} 3 \operatorname{Re}, \mathbf{d} 6 \operatorname{Re}$

Table 3 Chemical compositions of the white particles in Fig. 7 obtained by EPMA (at.\%)

\begin{tabular}{llllllllllll}
\hline Position & $\mathrm{Ni}$ & $\mathrm{W}$ & $\mathrm{Ta}$ & $\mathrm{Al}$ & $\mathrm{O}$ & $\mathrm{Cr}$ & $\mathrm{Co}$ & $\mathrm{Mo}$ & $\mathrm{Re}$ & $\mathrm{Si}$ & $\mathrm{Hf}$ \\
\hline 1 & 1.2653 & - & 0.3264 & 24.1036 & 57.4582 & 0.0685 & 0.0932 & 0.0100 & - & - & 16.6748 \\
2 & 0.2151 & - & 0.1357 & 31.9700 & 52.8284 & 0.0100 & 0.0327 & - & - & - & 14.8081 \\
3 & 1.0125 & 0.0021 & 0.5241 & 26.8082 & 55.6472 & - & 0.0582 & 0.0096 & - & - & 15.9381 \\
\hline
\end{tabular}

the ceramic oxides $\alpha-\mathrm{Al}_{2} \mathrm{O}_{3}$ bonded to the alloy bottom, which is consistent with the results of SEM and EPMA.

In the case of the interface reactions, the interface reaction degree decreases as the level of Re increases. Accordingly, it can be concluded that Re has a certain inhibitory effect on the interfacial reactions. On the one hand, the diffusion activation energy of $\mathrm{Re}$ in $\mathrm{Ni}$ is the largest among all elements and Re has a lower diffusion coefficient, which makes Re can significantly reduce the diffusion process of other elements [25-27]. On the other hand, Re can increase the oxidization resistance of superalloys. As reported by Fullagar et al., Re could reduce the oxidation rate by slowing down the diffusion of reactive elements into the oxidation zone, so as to improve the oxidation resistance of the alloys [28, 29]. In present work, $\mathrm{Hf}$ and $\mathrm{Al}$ in the melt diffuse to the alloy-ceramic interface when the superalloy melts and then react with $\mathrm{SiO}_{2}$ in the ceramic surface, thus forming $\mathrm{HfO}_{2}$ and $\mathrm{Al}_{2} \mathrm{O}_{3}$ at the interface. Owing to the inhibition of Re, the diffusion rate of $\mathrm{Hf}$ and $\mathrm{Al}$ decreases. So the diffusion of $\mathrm{Hf}$ and $\mathrm{Al}$ to the interface slows down gradually with Re content increasing, resulting in the formation of $\mathrm{HfO}_{2}$ and $\mathrm{Al}_{2} \mathrm{O}_{3}$ decreases gradually. When the content of Re is $6 \mathrm{wt} \%$, the interface reaction is the weakest. Since the low content of $\mathrm{Hf}$ and high content of Re in the melt, it is difficult for Hf diffuse to the interface. So in this case, no $\mathrm{HfO}_{2}$ phase is formed at the interface. For the alloy without $\mathrm{Re}, \mathrm{Hf}$ and $\mathrm{Al}$ diffuse rapidly to the interface, which makes $\mathrm{HfO}_{2}$ and $\mathrm{Al}_{2} \mathrm{O}_{3}$ form quickly at the interface. At this time, the content of $\mathrm{HfO}_{2}$ and $\mathrm{Al}_{2} \mathrm{O}_{3}$ generated is the highest. The whole interfacial reaction process can be schematically described in Fig. 11. 

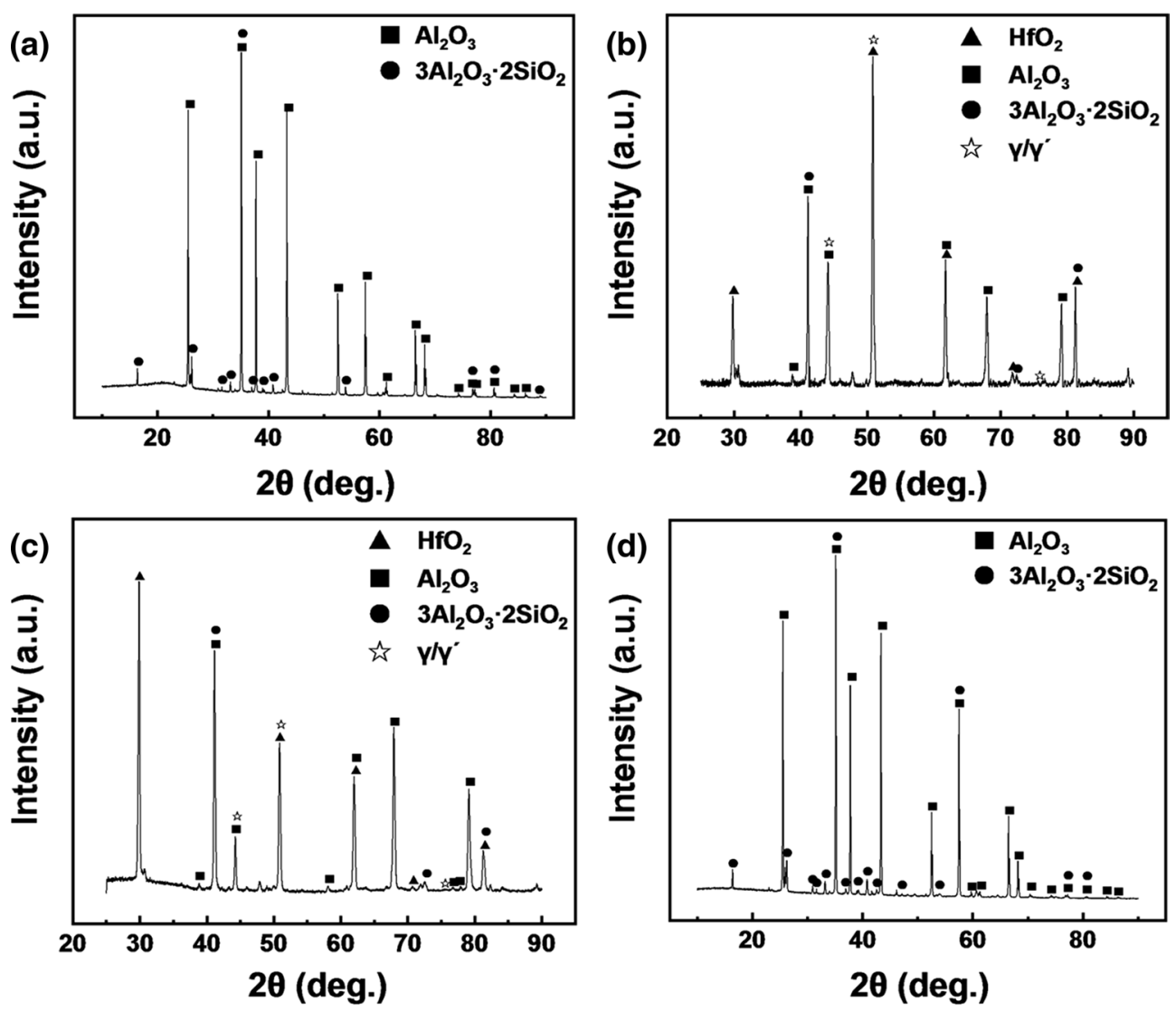

Fig. 8 XRD patterns of the ceramic surfaces: a $0 \operatorname{Re}, \mathbf{b} 1.5 \operatorname{Re}, \mathbf{c} 3 \operatorname{Re}, \mathbf{d} 6 \operatorname{Re}$

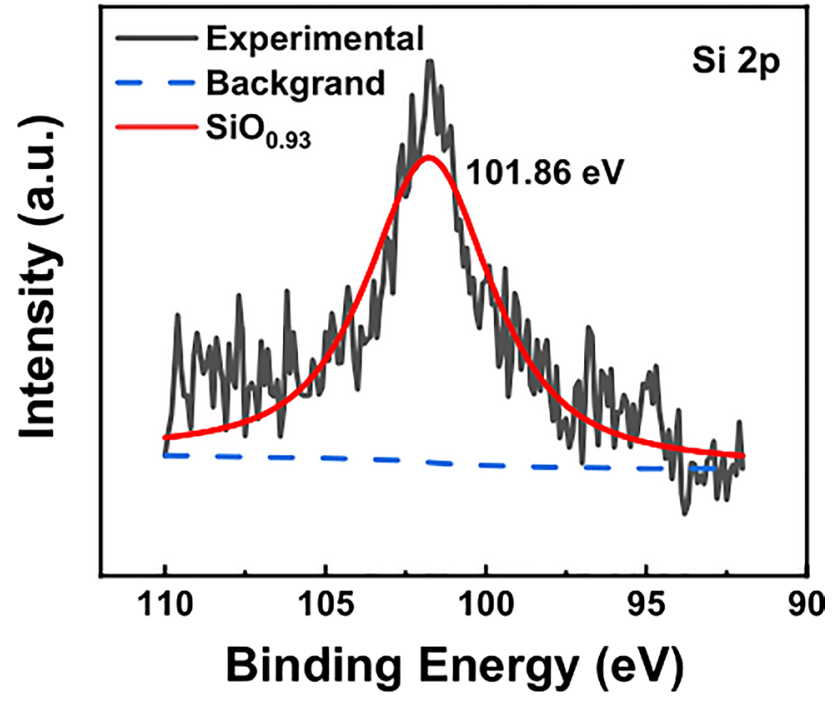

Fig. 9 Si $2 p$ XPS spectrum of the 3Re alloy bottom

In the case of the viscous sand, the particles of ceramic surface fall off and adhere to the reaction layer or alloy surface, thereby forming a viscous sand layer after the cooling. Previous studies have pointed out that the thermal expansion
Table 4 Binding energies of related phases in literature [23]

\begin{tabular}{llll}
\hline Element & Phase & $\begin{array}{l}\text { Binding energy } \\
(\mathrm{eV})\end{array}$ & Literature data \\
\hline $\mathrm{Al}$ & $\alpha-\mathrm{Al}_{2} \mathrm{O}_{3}$ & $\mathrm{Al} 2 p$ & 74.70 \\
& $\mathrm{Al}_{2} \mathrm{O}_{3}$ & $\mathrm{Al} 2 p$ & 73.62 \\
$\mathrm{O}$ & $\alpha-\mathrm{Al}_{2} \mathrm{O}_{3}$ & $\mathrm{O} 1 s$ & 532.20 \\
& $\mathrm{Al}_{2} \mathrm{O}_{3}$ & $\mathrm{O} 1 s$ & 531.60 \\
$\mathrm{Si}$ & $\mathrm{SiO}_{0.93}$ & $\mathrm{Si} 2 p$ & 101.90 \\
\hline
\end{tabular}

coefficient between the ceramic and the alloy does not match, so the internal stress will be generated during the cooling. Thus, the surface ceramic particles will fall off and adhere to the surface of the alloy, forming the viscous sand layer [30]. Additionally, there are always some dissolved ceramic oxides at the alloy-ceramic interface under high temperatures, and the dissolved ceramic oxides will adhere to the surface of the alloy or react with alloying elements [31, 32]. The two mechanisms may be the reasons for the formation of viscous sand.

However, it is obvious from Fig. 4 that the degree of viscous sand at the alloy bottom decreases with the increase in Re content, demonstrating that the viscous sand degree is 

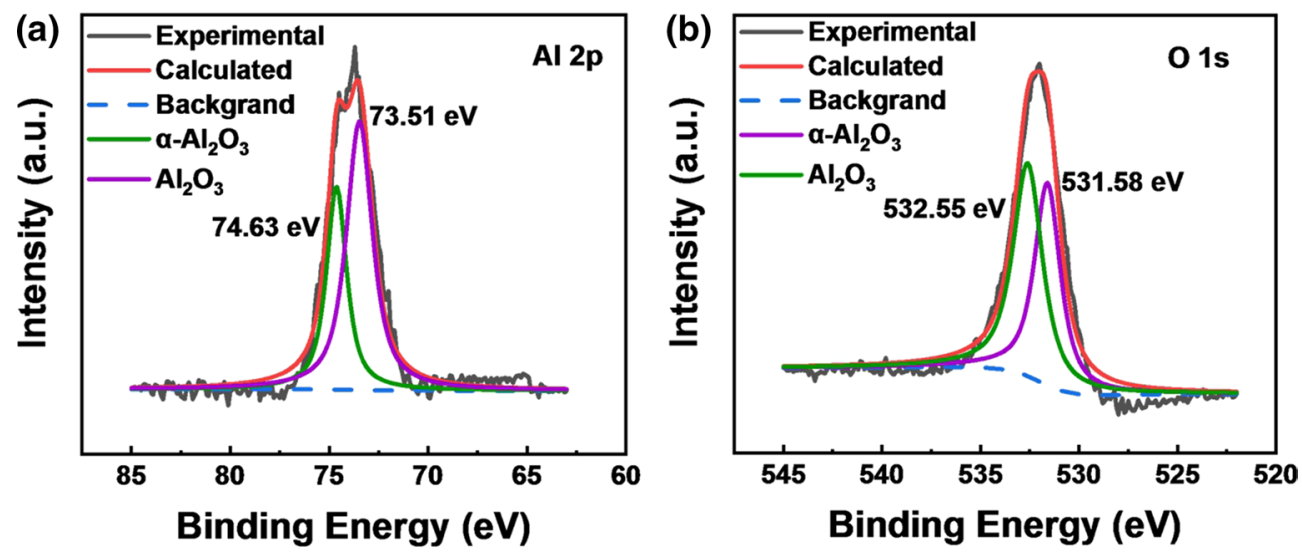

Fig. $10 \mathrm{Al} 2 p(\mathbf{a})$ and $\mathrm{O} 1 s(\mathbf{b})$ XPS spectra of the 3Re alloy bottom

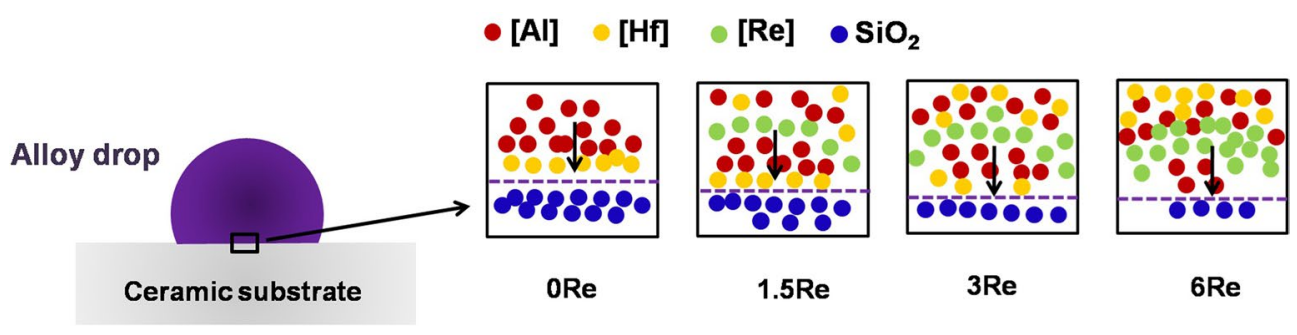

Fig. 11 Schematic diagram of the whole interfacial reaction process

also bound up with the content of Re. The ceramic surface is not completely dense, and there are a lot of pores on the surface (Fig. 1a). The alloy drop will move on the ceramic surface and penetrate into the pores by capillary action, and then mix with the ceramic particles to form viscous sand after the cooling. Whether the alloy drop can penetrate into the pores depends on whether the alloy drop can overcome the critical pressure of capillary action [33,34], and the critical pressure can be expressed by the following formula [34, 35]:

$P \geq P_{\mathrm{g}}-P_{\mathrm{c}}=P_{\mathrm{g}}-\left(2 \sigma_{\mathrm{lv}} \cos \theta\right) / r$,

where $P$ is the critical pressure, $P_{\mathrm{g}}$ is the gas pressure in the pores, which hinders the penetration of the alloy drop into the pores, $P_{\mathrm{c}}$ is the capillary force, $\sigma_{\mathrm{lv}}$ is the surface tension of the molten alloy, $r$ is the radius of the capillary, $\theta$ is the wetting angle. Based on Eq. (1), it can be seen that the critical pressure $P$ is only related to the wetting angle $\theta$ when other conditions remain unchanged.

The wetting angle increases when Re content increases, so the critical pressure increases, which suggests that the alloy drop is not easy to penetrate into the pores. Therefore, it is not easy to form the viscous sand when the content of $\mathrm{Re}$ is $6 \mathrm{wt} \%$. Conversely, the wetting angle is the smallest for the alloy without Re, so the critical pressure is the smallest.

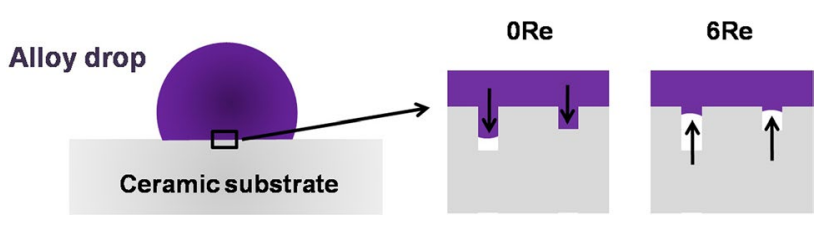

Fig. 12 Schematic diagram of the penetration of the molten alloy into the ceramic

The alloy drop has a greater tendency to penetrate into the pores, so forming a more serious viscous sand layer at the ORe alloy bottom. Consequently, it can be concluded that the wetting angle of the molten alloy on the ceramic surface plays a dominant role in the formation of viscous sand at the interface. The schematic diagram of the penetration of the molten alloy into the ceramic is presented in Fig. 12.

\section{Conclusions}

The effect of $\mathrm{Re}$ on interactions and wettability between molten superalloy and $\mathrm{Al}_{2} \mathrm{O}_{3}$-based ceramic mould were studied comprehensively in present work, and the influence mechanisms of Re were also discussed in detail. The following conclusions can be drawn from this work: 
(1) The wettability of the alloy/ceramic system gradually deteriorates with the content of Re increases from 0 to $6 \mathrm{wt} \%$.

(2) For the alloys with Re content of $0,1.5$ and $3 \mathrm{wt} \%$, Hf and $\mathrm{Al}$ react with $\mathrm{SiO}_{2}$ to form $\mathrm{HfO}_{2}$ and $\mathrm{Al}_{2} \mathrm{O}_{3}$ at the interface. However, only $\mathrm{Al}_{2} \mathrm{O}_{3}$ phase is formed when the content of $\operatorname{Re}$ is $6 \mathrm{wt} \%$. The thickness of reaction layer remarkably decreases with Re content increasing.

(3) Re inhibits the interface reactions to a certain extent. The lowest $\mathrm{Al}_{2} \mathrm{O}_{3}$ content is formed for the $6 \mathrm{Re}$ alloy while the most $\mathrm{Al}_{2} \mathrm{O}_{3}$ content is formed for the $0 \mathrm{Re}$ alloy. Moreover, the reaction between $\mathrm{Hf}$ and $\mathrm{SiO}_{2}$ is completely inhibited by $\mathrm{Re}$ when the content of $\mathrm{Re}$ is $6 \mathrm{wt} \%$.

Acknowledgements This study was financial supported by the National Key R\&D Program of China (No. 2017YFA0700704), the National Science and Technology Major Project (No. 2017-VI-0003-0073) and the National Natural Science Foundation of China (Nos. 51601192, 5161188 and 51701210).

\section{References}

[1] R.C. Reed, The Superalloys Fundamentals and Applications (Cambridge University Press, Cambridge, 2006)

[2] M.R. Jahangiri, M. Abedini, Mater. Des. 64, 588 (2014)

[3] L. Zheng, G. Zhang, T.L. Lee, M.J. Gorley, Y. Wang, C. Xiao, Z. Li, Mater. Des. 61, 61 (2014)

[4] S. Pattnaik, D.B. Karunakar, P.K. Jha, J. Mater. Process. Technol. 212, 2332 (2012)

[5] S.J. Yao, D.Z. Tang, X.G. Liu, X. Li, L.L. Wang, C.X. Cao, F.Z. Ding, H. Chen, J. Aeronaut. Mater. 35, 1 (2015)

[6] X.Y. Chen, Y.Z. Zhou, T. Jin, X.F. Sun, MATEC Web Conf. 14, 13008 (2014)

[7] M.R. Orlov, Russ. Metall. 1, 56 (2008)

[8] Q. Li, J.X. Song, D.G. Wang, Q. Yu, C.B. Xiao, Rare Met. 30, 405 (2013)

[9] L. Zheng, C.B. Xiao, G.Q. Zhang, G.H. Gu, X. Li, X.G. Liu, M. Xue, D.Z. Tang, J. Aeronaut. Mater. 32, 10 (2012)
[10] F. Valenza, M.L. Muolo, A. Passerone, J. Mater. Sci. 45, 2071 (2010)

[11] J.S. Yao, D.Z. Tang, X.G. Liu, C.B. Xiao, X. Li, C.X. Cao, Mater. Sci. Forum 747, 765 (2013)

[12] Y. Zi, J. Meng, C.W. Zhang, Y.H. Yang, Y.Z. Zhou, Y.T. Ding, J. Alloys Compd. 789, 472 (2019)

[13] X.Y. Chen, L. Xiao, J.B. Yu, B.D. Sun, F. Li, Spec. Cast. Nonferrous Alloys 36, 844 (2016)

[14] X.Y. Chen, Y.Z. Zhou, T. Jin, X.F. Sun, J. Mater. Sci. Technol. 32 177 (2016)

[15] G.W. Liu, M.L. Muolo, F. Valenza, A. Passerone, Ceram. Int. 36, $177(2010)$

[16] X.F. Sun, T. Jin, Y.Z. Zhou, Z.Q. Hu, Mater. China 31, 1 (2012)

[17] K.D. Xu, Z.M. Ren, C.J. Li, Rare Met. 33, 11 (2014)

[18] M. Xue, Dissertation, Tsinghua University, 2007

[19] Chinese Government Standard, GB/T 1966-1996, 1996

[20] X.H. Zheng, Dissertation, JiLin University, 2010

[21] I.A. Aksay, C.E. Hoge, J.A. Pask, J. Phys. Chem. 78, 1178 (1974)

[22] I. Barin, G. Platzki, Wiley Online Library, 1989

[23] NIST X-ray Photoelectron Spectroscopy Database, NIST Standard Reference Database 20

[24] T. Sun, X. Zhang, Inorganic Chemistry (Metallurgical Industry Press, Beijing, 2011)

[25] A. Mottura, R.T. Wu, M.W. Finnis, Acta Mater. 56, 2669 (2008)

[26] A. Mottura, M.W. Finnis, R.C. Reed, Acta Mater. 60, 2866 (2012)

[27] C.L. Fu, R.C. Reed, A. Janotti, M. Krcmar, Superalloys 2004, 867 (2004)

[28] P.S. Burkholder, M.C. Thomas, D.J. Frasier, in The Institute of Materials 3rd International Charles Parsons Turbine Conference, UK, 1995

[29] K.P.L. Fullagar, K. Harris, G.L. Erickson, R.W. Broomfield, M. Hulands, S.L. Sikkenga, J. Eng. Gas Turbines Power 118, 380 (1996)

[30] X.F. Liu, W.J. Guo, Y.C. Lou, G.Q. Su, B. Yu, Foundry 59, 1293 (2010)

[31] N. Eustathopoulos, M.G. Nigholas, B. Drevet, Wettability at High Temperatures (Elsevier, Oxford, 1999)

[32] W. Yan, A. Schmidt, S. Dudczig, T. Wetzig, Y.W. Wei, Y.W. Li, S. Schafföner, C.G. Aneziris, J. Eur. Ceram. Soc. 38, 2164 (2018)

[33] Y.H. Pan, Min. Mach. 39, 118 (2011)

[34] W.T. Qu, Foundry Technology (Higher Education Press, Xi'an, 1994)

[35] J.R. Jiang, X.Y. Liu, J. Mater. Process. Technol. 189, 247 (2007) 